Research Article

\title{
Direct Shear Creep Characteristics and Microstructure of Fiber-Reinforced Soil
}

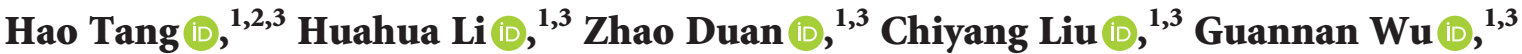 \\ and Jinzhi Luo $\mathbb{1}^{1,3}$ \\ ${ }^{1}$ College of Geology and Environment, Xi'an University of Science and Technology, Xi'an 710054, China \\ ${ }^{2}$ Geological Research Institute for Coal Green Mining, Xi'an University of Science and Technology, Xi'an 710054, China \\ ${ }^{3}$ Shaanxi Provincial Key Laboratory of Geological Support for Coal Green Exploitation, \\ Xi'an University of Science and Technology, Xi'an 710054, China
}

Correspondence should be addressed to Huahua Li; 18209212056@stu.xust.edu.cn

Received 18 September 2020; Revised 7 December 2020; Accepted 23 December 2020; Published 13 January 2021

Academic Editor: Guoyang Fu

Copyright (c) 2021 Hao Tang et al. This is an open access article distributed under the Creative Commons Attribution License, which permits unrestricted use, distribution, and reproduction in any medium, provided the original work is properly cited.

Fiber-reinforced soil is an excellent engineering material that has become a focus of research. Most studies focus on the conventional mechanical properties of reinforced soil, such as its tensile, compressive, and shear strength, and rarely study its creep-related mechanical properties. However, when such soil is used as backfill, the creep effect should not be ignored. This study explored the characteristics of creep mechanics in reinforced soil, the fiber-reinforcement mechanism, and the dynamics of microstructures before and after creep tests. Direct shear creep tests were carried out using a direct shear creep tester on soil reinforced with natural palm fibers of equal length $(1.5 \mathrm{~cm})$ in different amounts $(0 \%, 0.2 \%, 0.6 \%, 1.0 \%)$. Microscale tests were carried out on the reinforced soil samples before and after the creep tests by polarized light and scanning electron microscopy. The results show that the fiber reinforcement can restrain the deformation and enhance the long-term strength of soil. However, a nonlinear relationship between the reinforcement effect and fiber content was found, with $0.6 \%$ being the optimal content. Palm fibers have rough surfaces, grooves, and independent pore chambers, which increase the effective contact area and interaction with the soil. With increases in fiber content, the fibers interweave to form a nestled network structure, which increases the strength and integrity of the soil. Fiber addition changes the microstructure of the soil pores; the proportion of large pores decreases and that of small pores increases. Under the effect of creep, the pore changes follow the principle of pore homogenization; large pores are destroyed and transformed into small pores, causing the porosity of reinforced soil to decrease faster and be less porous than unreinforced soil. This research can provide technical reference for the engineering application of palm fiber-reinforced soil.

\section{Introduction}

In recent years, fiber-reinforced soil technology has developed rapidly and has been widely used in engineering to improve soil masses. Test results show that fiber reinforcement can inhibit soil fracture development and enhance soil toughness, deformation resistance, and strength $[1,2]$. Moreover, a uniform distribution of fibers in soil that makes full contact with the soil particles can make the mechanical properties of fibrous soil close to isotropic and enhance its integrity [3, 4]. At present, with global environmental and energy problems increasingly prominent, people are paying greater attention to the application of environmentally friendly materials in engineering. The use of plant fibers, such as bamboo, palm coconut, wood, and hemp fibers (jute, sisal, ramie, flax, etc.), in composite materials has become a hot research topic [5-8]. Palm fibers have medium strength, high elongation, wear and corrosion resistance, low cost, and good mechanical properties [9].

Fiber-reinforced soil is an excellent engineering material and the study of its mechanical properties has become a hot research topic in the geotechnical field. Ranjan et al. [10] studied medium- and coarse-sand fiber-reinforced soil through indoor triaxial experiments. The results showed that 
the peak strength of fiber-reinforced soil increases with fiber content, and its residual strength is higher than that of unreinforced soil. In addition, the shear strength of reinforced soil is linearly related to fiber length. Prabakar and Sridhar [11] studied the influences of factors such as sisal fiber content and length on clay strength and compaction characteristics with through triaxial and compaction tests. Yetimoglu et al. [12] conducted triaxial compression tests on fiber-reinforced sand, showing that its strength was significantly higher than that of unreinforced sand. Vinod et al. [13] conducted a triaxial undrained test to explore the reinforcing effect of coconut shell fiber on soft clay. The test results showed that the optimal fiber-reinforcing ratio is $1 \%$ and that the reinforcing effect is more obvious under high confining pressure. Adili et al. [14] reported the optimal reinforcement ratio of papyrus to be $10 \%$, in terms of increasing the friction and cohesion between silty soil and sand. Zhu et al. [15] carried out direct shear and triaxial compression tests to study the mechanical properties of fiber-reinforced soil. They analyzed the interaction between fiber and surrounding soil during shear testing to clarify the strengthening process and mechanism of fiber addition. Chen et al. [16] studied the shear characteristics of reinforced filled soil and carried out a large-scale triaxial test. The results show that the shear deformation tended towards strain hardening with increases in the number of layers and confining pressure. The number of geogrid layers affects the sliding surface type of geogrid-earth interfaces. Lei et al. [17] conducted a series of unconfined compressive strength experiments under the conditions of optimal water content and maximum dry density to explore the compressive strength of basalt fiber-reinforced soil. The test results show that basalt fiber can effectively improve the unconfined compressive strength of cohesive soil and that its optimal parameters have a content of $0.25 \%$ and a length of $12 \mathrm{~mm}$. Basalt fiber-reinforced clay has a "poststrong" characteristic. Wang et al. [18-20] carried out a lot of triaxial tests to study the mechanical properties of fiber-reinforced soil and tried to develop a new numerical analysis of fiber-reinforced soil based on the equivalent additional stress concept. Tang et al. [21] showed that polypropylene fiber causes obvious improvement to the tensile strength of soil. Strain can continue to increase after soil failure, giving the soil sample higher toughness. Hao et al. [22] carried out triaxial experiments on wheat straw-reinforced cohesive soil and found that the shear strength and deformation resistance of the soil were significantly improved, while its deformation and crack propagation were effectively inhibited.

Most of the above studies have carried out valuable research on the strength and deformation characteristics of reinforced soil based on uniaxial or triaxial compression or shear tests; however, there has been little research on creep characteristics. Reinforced soil is widely used in highway foundations, railway foundations, soft foundations, and slope engineering as a type of backfill soil. A series of problems, such as ground settlement, subgrade settlement deformation, and slope instability, can occur if its creep effect is not fully considered, which can pose a great threat to the safety of property.
At present, there are many valuable studies on the creep characteristics of soil. To study the creep characteristics of clay, Li and Peng [23] carried out a triaxial drained shear creep test on undisturbed and remolded clay and discussed the creep characteristics of clay during initial loading, unloading, and repeated loading. Wang et al. [24] carried out a series of indoor triaxial consolidation and drainage creep tests on Jingyang remolded loess in Shaanxi Province by means of a triaxial creep tester. They explored the creep characteristics of remolded loess with different water contents and confining pressures under a $90 \%$ compaction degree and established two kinds of empirical creep models. Through a series of creep shear tests, Wen and Jiang [25] discussed the creep characteristics of natural clayey soil containing gravel in the residual state. The test results showed that the presence of gravel had a significant impact on the creep behaviour of clayey soil. Shun et al. [26] conducted shear creep tests on landslide soils in the Three Gorges Reservoir area to study the creep characteristics of clastic soils in the eluvial state, and they discussed creep behavior of soil samples under different shear stress conditions. Kaddouri et al. [27] conducted compression tests at various temperatures and vertical stresses to study the effect of effective stress and temperature on the creep characteristics of saturated compacted cohesive soil. The results show that the compression and expansion indices are affected by temperature, and the yield stress decreases with increases in temperature. Tang et al. [28] used triaxial creep tests to explore the creep characteristics of loess with different water contents and confining pressures. They proposed a binary creep model to describe the creep characteristics based on fractional-order calculus and damage mechanics. However, creep effects in reinforced soil have rarely been studied.

The mechanical properties of soil are closely related to its the structural characteristics [29-31]. The method of combining macromechanical experiment and micromechanical test technology to analyze the soil structure characteristics and elaborate the macro mechanical mechanism is very effective. Bai et al. [32, 33] defined directional indicators and used digital image processing technology to analyze scanning electron microscopy (SEM) images of clay soils and studied the directional properties of clay particles in consolidated undrained shear tests. Wang et al. [34] conducted unconsolidated-undrained (UU) triaxial tests and SEM analysis to study the mechanical behavior of Hefei clayey soil strengthened with wheat straw fiber and lime and analyze the microscopic mechanism of the strengthened soil. Liu et al. [35] used SEM to conduct microscopic experiments on clay and analyzed its geometric parameters, probability entropy, probability distribution index, and fractal dimension after shear. They analyzed the influences of the threshold value, magnification factor, analysis area, and other factors on the microcosmic parameters of the clay under the electron microscope. Lioret et al. [36] studied the microstructure of bentonite by the mercury intrusion method, SEM, and macromechanical tests. To study the microstructural changes in natural soft clay under accelerated creep conditions, Lei et al. [37] carried out consolidated undrained triaxial tests under static and cyclic 
loads and obtained the microstructural parameters of the samples by means of mercury injection and SEM. Xie et al. [38] used triaxial creep tests to study loess soils from Xi'an, China. By obtaining SEM images of vertical and crosssections of samples, the changes in particle and pore structures under different coaxial stresses and confining pressures were analyzed. Zhang et al. [39] studied the distribution of red clay particles and pores after creep tests.

This study explores the characteristics of creep and changes in the microscopic pore structure of palm fiberreinforced soil. The creep-related mechanical properties of palm fiber-reinforced soil were studied through direct shear creep tests. The interfacial mechanism of reinforced soil was explored using polarized light microscopy and SEM, and the characteristics of the microscopic pores of reinforced soil were quantitatively analyzed.

\section{Materials and Methods}

\subsection{Materials}

2.1.1. Loess. The loess used in the test was $Q_{2}$ loess from the Jingyang South Loess Plateau of Shaanxi Province. The soil samples were deep yellow in color, compact, and uniform in quality and contained a small amount of large pores. Before the test, the loess was air-dried and screened to remove debris, dried and crushed, and then screened through a $2 \mathrm{~mm}$ hole screen. To ensure dryness, pretreated samples were placed in plastic wrap for preservation. The basic physical properties of the remolded loess are shown in Table 1.

2.1.2. Palm Fiber. The experimental palm fiber is shown in Figure 1. It was natural palm fiber produced in Guangxi. Its Young's modulus, elongation at breakage, and fracture strength scope were $0.44-1.09 \mathrm{GPa}, 14.68-23.45 \%$, and $89-222 \mathrm{MPa}$, respectively. The fiber diameter was $0.02-0.05 \mathrm{~mm}$ and its length was $1.5 \mathrm{~cm}$.

2.2. Sample Preparation. Soil samples were prepared with fiber length of $1.5 \mathrm{~cm}$ and fiber contents of $0 \%, 0.2 \%, 0.6 \%$, and $1.0 \%$. The moisture content of the reinforced loess was controlled at $14.2 \%$. To prepare samples, we determined the weights of the soil, water, and reinforcement used to prepare each ring knife and then mixed the palm fiber evenly with the soil. To mix well, we sprinkled some soil evenly on the bottom of a dry tray and then sprinkled some palm fiber evenly on top and stirred it until evenly mixed. Finally, we sprayed distilled water from a spray bottle onto the soil and stirred it fully for $30 \mathrm{~min}$. Then, we sealed it in plastic bags and placed them in a constant humidity container for $24 \mathrm{~h}$ for later use. The test parameters are shown in Table 2.

2.3. Test Method. A triple direct shear creep instrument (Zlb-1 type) was used for the tests, as shown in Figure 2. The sample diameter and height were $61.8 \mathrm{~mm}$ and $20 \mathrm{~mm}$, respectively. According to the Chinese standard for soil testing (GB/T 50123-2019), quick shear tests were carried
TABLE 1: Test results of the physical properties of loess in its natural state.

\begin{tabular}{lccccc}
\hline$\omega^{*}(\%)$ & $\rho^{*}\left(\mathrm{~g} / \mathrm{cm}^{3}\right)$ & $\omega_{\mathrm{L}}{ }^{*}(\%)$ & $\omega_{\mathrm{P}}{ }^{*}(\%)$ & $c^{*}(\mathrm{kPa})$ & $\varphi^{*}\left({ }^{\circ}\right)$ \\
\hline 14.2 & 1.57 & 27.8 & 18.4 & 32.27 & 28.62 \\
\hline
\end{tabular}

${ }^{*} \omega$ : natural moisture content; $\rho$ : natural density; $\omega_{\mathrm{L}}$ : liquid limit; $\omega_{\mathrm{P}}$ : plastic limit; $c$ : cohesion; $\varphi$ : angle of internal friction.

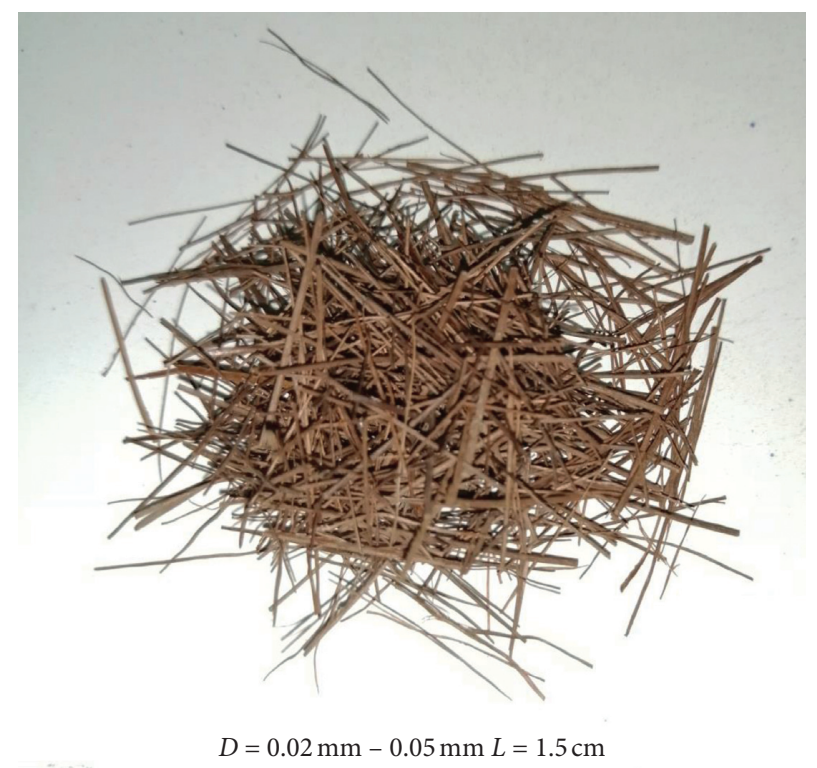

Figure 1: Palm fiber used in this study.

TABLE 2: Basic parameters of the samples.

\begin{tabular}{lcccc}
\hline Sample & $\begin{array}{c}\rho *(\mathrm{~g} / \\
\left.\mathrm{cm}^{3}\right)\end{array}$ & $\begin{array}{c}\omega * \\
(\%)\end{array}$ & $\begin{array}{c}\text { Fiber length } \\
(\mathrm{cm})\end{array}$ & $\begin{array}{c}\text { Fiber content } \\
(\%)\end{array}$ \\
\hline A & 1.57 & 14.2 & - & - \\
B1 & 1.57 & 14.2 & 1.5 & 0.2 \\
B2 & 1.57 & 14.2 & 1.5 & 0.6 \\
B3 & 1.57 & 14.2 & 1.5 & 1.0 \\
\hline
\end{tabular}

out under different consolidation pressures $(100 \mathrm{kPa}$, $200 \mathrm{kPa}, 300 \mathrm{kPa}$, and $400 \mathrm{kPa}$ ), and shear tests were carried out at a speed of $0.8 \mathrm{~mm} / \mathrm{min}$ to measure the shear strength of the reinforced soil at various consolidation pressures.

The direct shear creep tests adopted the graded loading method. The first-stage load was $40 \%$ of the peak shear strength and the load at each subsequent stage was increased by $10 \%$. The standard for creep stability is that the shear displacement is no more than $0.01 \mathrm{~mm} / \mathrm{d}$ under each shear load. After deformation stabilized, the next shear stress was applied until the soil sample reached shear failure.

\section{Results and Analysis}

3.1. Analysis of Strain-Time Curves. The test data were processed according to the Boltzmann linear superposition principle. Strain-time curves of reinforced soil with different fiber contents were obtained under different normal pressures. Creep data obtained at a normal phase pressure of $200 \mathrm{kPa}$ were selected for analysis, as shown in Figure 3. It 


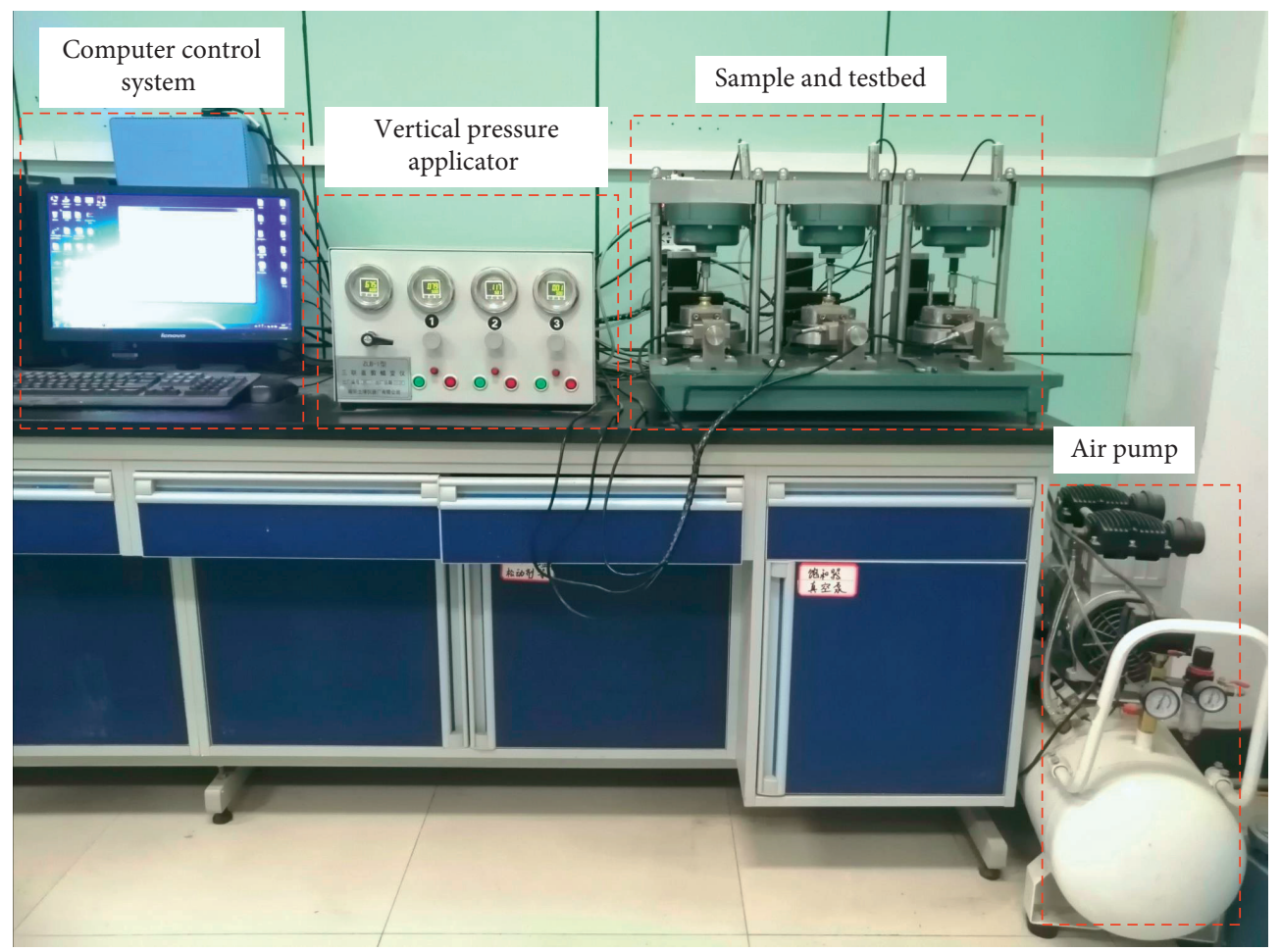

Figure 2: ZLB-1 triple straight-shear creep test apparatus.
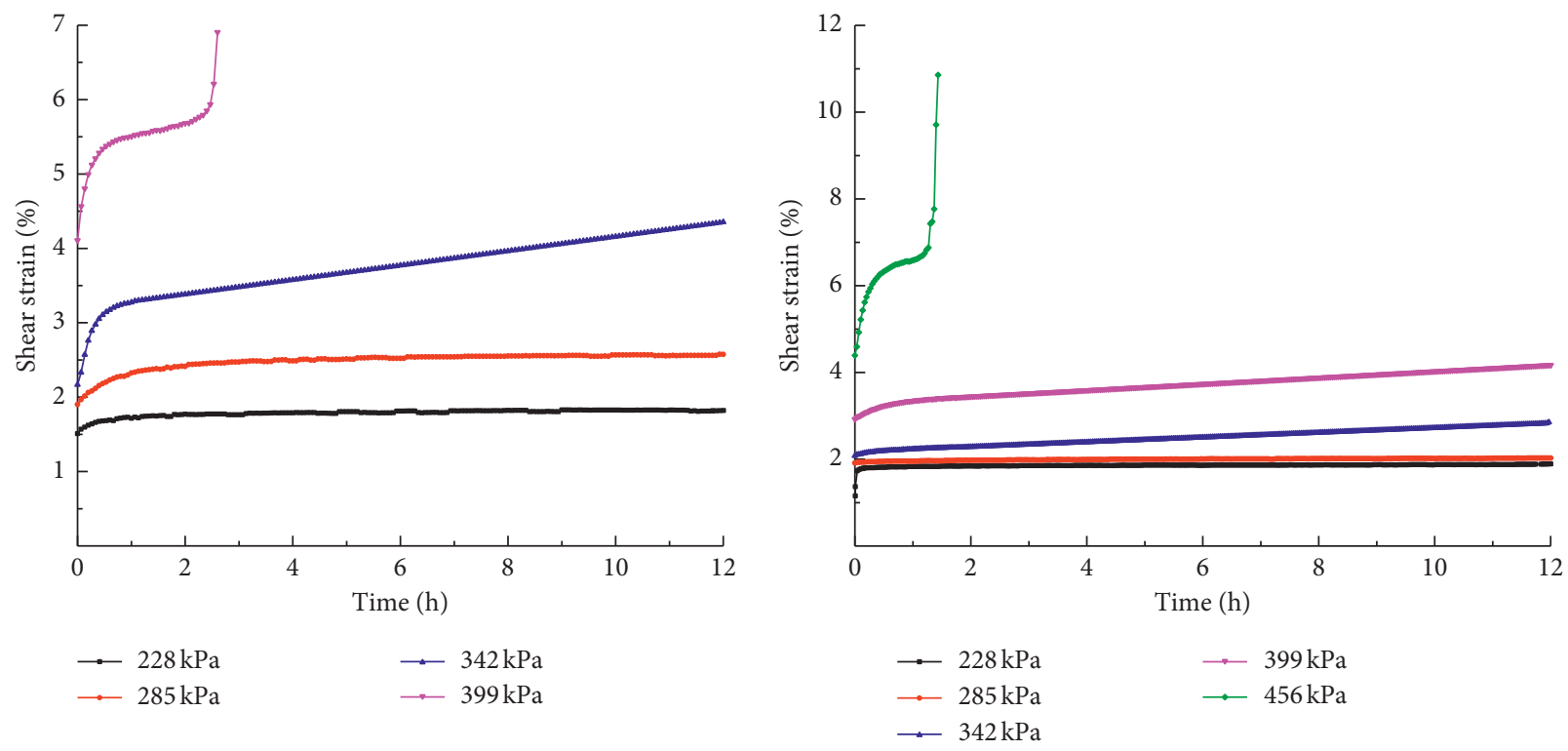

$\rightarrow 399 \mathrm{kPa}$

$\rightarrow 342 \mathrm{kPa}$

(a)

(b)

Figure 3: Continued. 


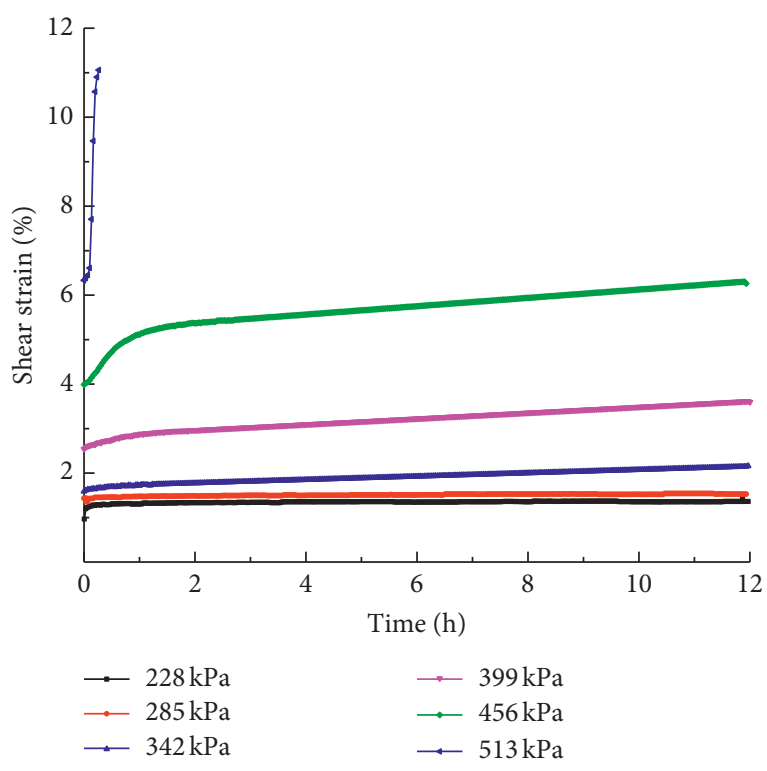

(c)

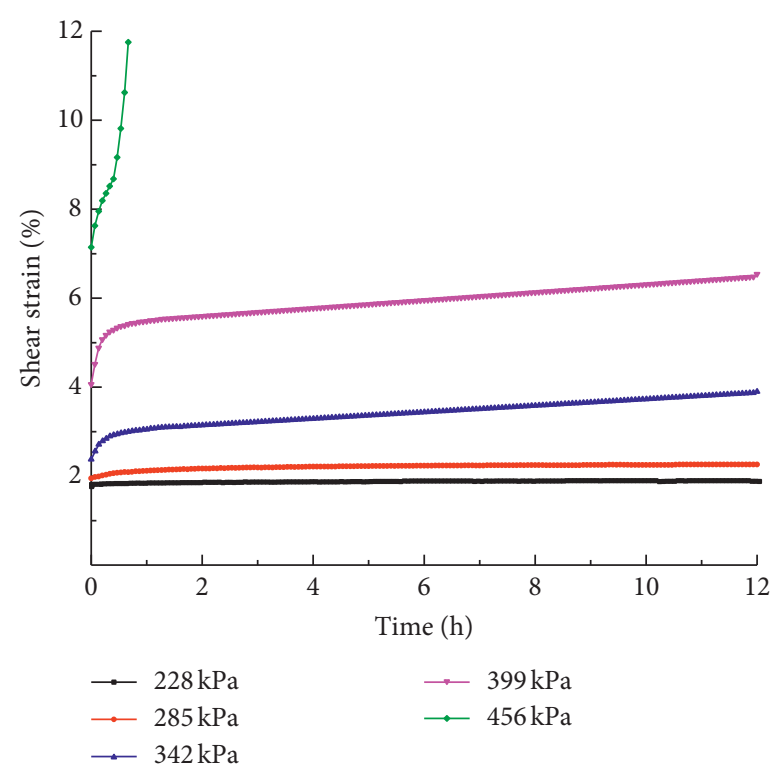

(d)

Figure 3: Strain-time curves of soil with various fiber contents. (a) Sample A (unreinforced); (b) Sample B1 (fiber content 0.2\%); (c) Sample B2 (0.6\%); and (d) Sample B3 (1.0\%).

can be seen from Figure 3 that the creep of reinforced loess with different fiber contents had the following characteristics:

(1) The fiber-reinforced soil had obvious creep deformation characteristics. When the shear stress level was low, attenuation creep was mainly observed, which eventually became stable with time. As the stress level increased, constant creep occurred. When the stress reached a high level, the sample entered the accelerated creep stage and was gradually destroyed.

(2) Deformation includes instantaneous deformation and creep deformation. At the moment of loading, the loess reinforced with different fiber contents underwent instantaneous deformation. Over time, creep deformation increased and the strain gradually stabilized.

(3) By comparing unreinforced soil with the three types of reinforced soil $(0.2 \%, 0.6 \%$, and $1.0 \%$ fiber), it can be seen that when the shear stress is low, the difference in creep deformation between the reinforced and unreinforced soil is low. With increases in shear stress, the effect of the reinforcement on creep deformation becomes increasingly obvious. The creep deformation of unreinforced soil was obviously greater than that of reinforced soil within a certain time. For example, the creep deformation of $0.2 \%$, $0.6 \%$, and $1.0 \%$ reinforced soil were $34.42 \%, 50.4 \%$, and $10.44 \%$ less than that of unreinforced soil within 36 hours.

(4) Under the same shear stress, as the fiber content increased, the creep deformation of soil first decreased and then increased. The creep deformation of sample B2 (fiber content $0.6 \%$ ) was less than that of B1 (fiber content $0.2 \%$ ) and B3 (fiber content $1.0 \%)$, although B3 had the greatest fiber content. The results show that the creep deformation of fiberreinforced soil was generally inhibited by increases in fiber content, but when the fiber content is beyond $0.6 \%$, the creep deformation of fiber-reinforced soil will not be further inhibited. Hence, this was the optimal amount of fiber reinforcement.

3.2. Analysis of Isochronous Stress-Strain Curves. Analysis of isochronous stress-strain curves obtained under different confining pressures shows that their trends are basically the same. To understand the creep characteristics of unreinforced and reinforced soil in more detail, the isochronous stress-strain curve obtained at $200 \mathrm{kPa}$ was taken as an example. Isochronous stress-strain curves of reinforced and unreinforced soil under different shear stresses are shown in Figure 4 .

The isochronous curve is linear at low stress, showing the characteristic of linear viscoelasticity, and the slope gradually increases with increases in fiber content. At a higher stress level, the curve is curvilinear and becomes more so with increases in stress. The nonlinear characteristics become more obvious and show the characteristics of nonlinear viscoplasticity.

In this paper, the isochronous stress-strain curve method is used to determine the long-term strength of reinforced soil and it is an approach that has been used extensively for the creep evaluation of materials [40,41]. It can be seen from the isochronous stress-strain curve that, under low shear stress, the curve is close to coincidence. So it can be considered that, 


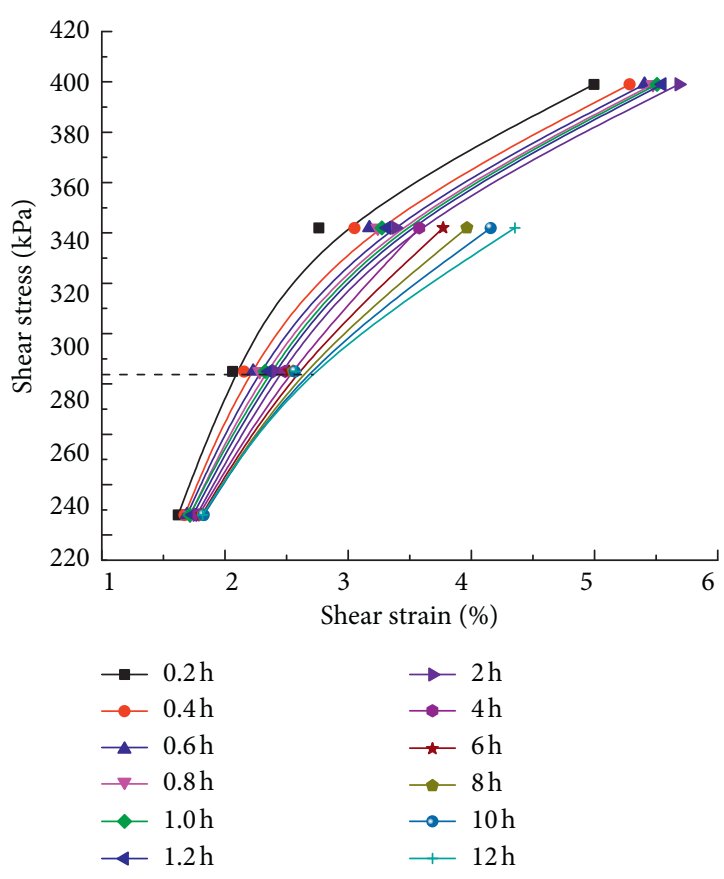

(a)

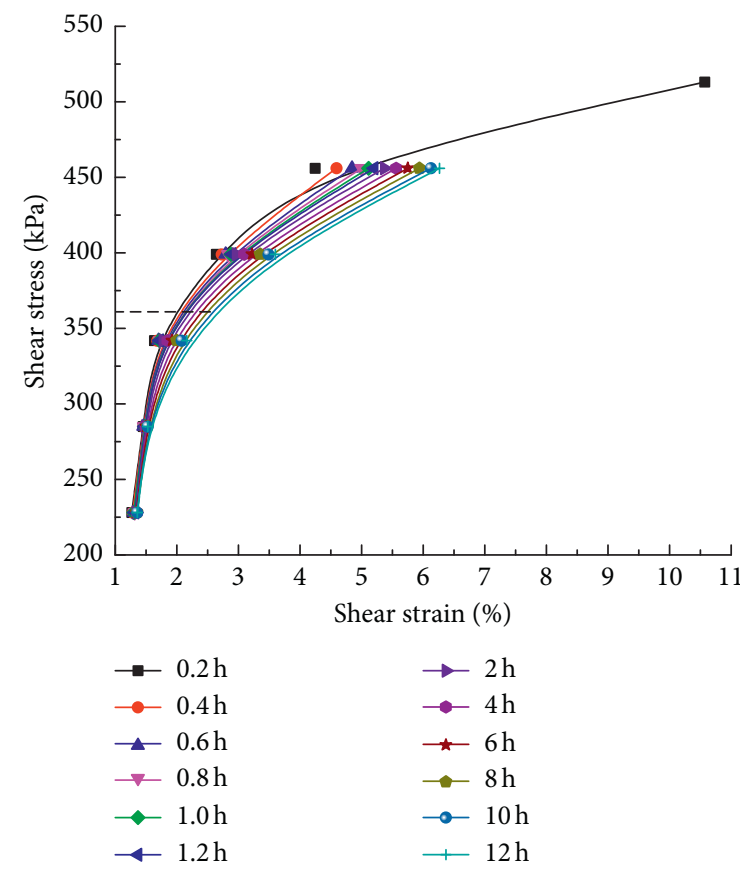

(c)

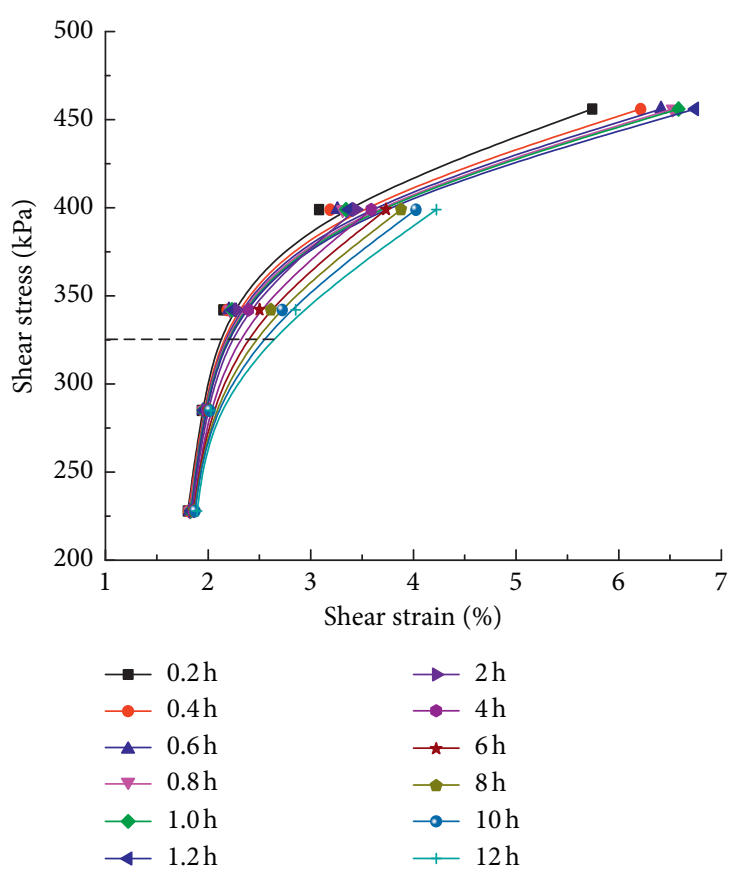

(b)

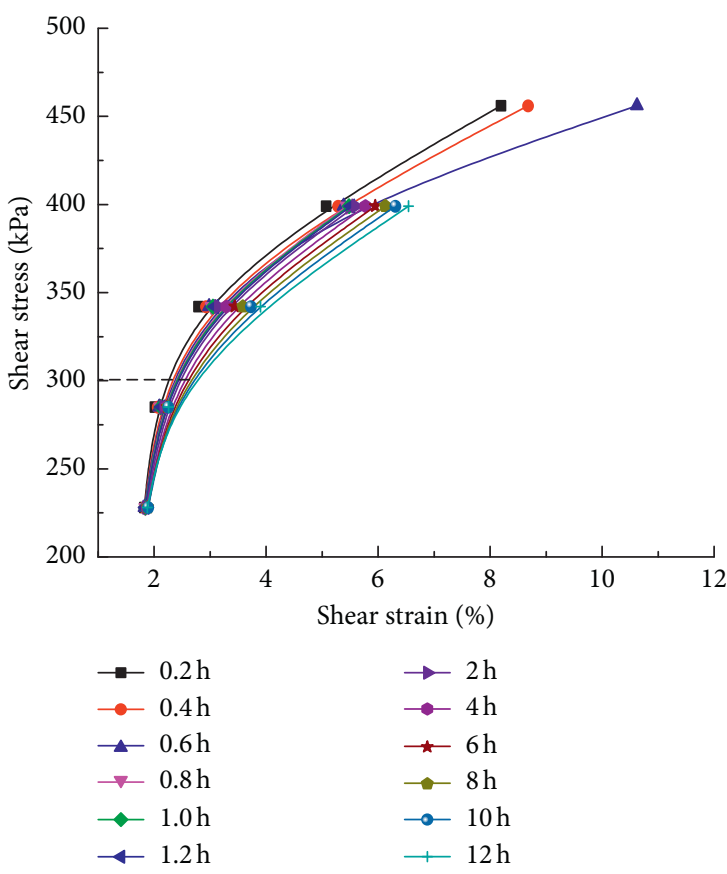

(d)

FIGURE 4: Stress-strain isochronous curves for soil with different fiber contents. (a) Sample A (unreinforced); (b) Sample B1 (fiber content $0.2 \%)$; (c) Sample B2 (0.6\%); and (d) Sample B3 (1.0\%).

under low stress, the creep of the sample has no obvious time effect. With the increase of shear stress, the distance between the curve clusters increases gradually, and the time effect of stress-strain increases continuously. The long-term strength of reinforced soil corresponds to the stress at the inflection point of the isochronous curves.

The long-term strength results are shown in Table 3. With increases in fiber content, the long-term strength of reinforced soil had an overall trend of improvement. The long-term strengths of reinforced soil (Samples B1, B2, and B3) were greater than that of unreinforced soil (Sample A) by $14.8 \%, 27.2 \%$, and $6.1 \%$, respectively. However, the longterm strength of soil did not increase linearly with fiber content. Although the fiber content of B2 was less than that of B3, its long-term strength was greater. This indicates that the long-term strength peaks at a fiber content of about $0.6 \%$. 
TABLE 3: Long-term strength of different samples.

\begin{tabular}{lccc}
\hline Sample & $\begin{array}{c}\text { Fiber length } \\
(\mathrm{cm})\end{array}$ & $\begin{array}{c}\text { Fiber content } \\
(\%)\end{array}$ & $\begin{array}{c}\text { Long-term strength } \\
(\mathrm{kPa})\end{array}$ \\
\hline A & - & - & 283 \\
B1 & 1.5 & 0.2 & 325 \\
B2 & 1.5 & 0.6 & 360 \\
B3 & 1.5 & 1.0 & 300 \\
\hline
\end{tabular}

3.3. Analysis of Shear Creep Rate Curves. It can be seen from Figure 2 that the creep curves of reinforced soil under various shear stresses include signs of attenuation creep and steady-state creep. In the decay creep process, the strain rate was always decreasing. When the shear stress was low $(228 \mathrm{kPa}$ and $285 \mathrm{kPa})$, the strain rate decayed to a constant close to zero. When the shear stress was high $(342 \mathrm{kPa}$, $399 \mathrm{kPa}$, and $456 \mathrm{kPa}$ ), the strain rate attenuated to a larger constant. This constant strain rate occurred in the second stage of creep and the steady-state creep stage. Figure 5 shows the steady-state creep rate under different shear stresses. It can be seen that the creep rate of composite soil with added fiber was significantly lower than that of nonreinforced soil. At the same fiber content, the creep strain rate increased with increases in shear stress, and the stressstrain rate relationship was obviously nonlinear. Under the same shear stress, the creep strain rate tended to decrease with increases in fiber content. It shows that the addition of fiber can delay creep deformation and improve the creeprelated mechanical properties of soil.

3.4. Microstructure of Palm Fiber-Reinforced Soil. The creep test results show that the reinforcement significantly improved the long-term strength of soil, restraining its deformation and reducing the creep rate. The long-term strength of reinforced soil was higher than that of nonreinforced soil. At the same shear stress load, the creep rate and creep deformation of reinforced soil were lower than those of unreinforced soil. This is mainly related to changes in the microstructure of fiber-reinforced soil.

3.4.1. Basic Morphology of Palm Fiber. The soil samples were observed with a polarizing microscope. As shown in Figures 6 and 7(a), the palm fiber was cylindrical with uneven rough surfaces and raised ridges down its length. Grooves occurred between the ridges, and there were many independent holes in the grooves. Under the action of friction and extrusion, soil particles became embedded into the grooves and chambers, thereby increasing the effective contact area and enhancing the interaction between the reinforcement and soil. When reinforced soil was stressed, sliding between the fibers and soil particles occurred and caused interfacial shear stress, which was mainly influenced by the interfacial friction and bonding force [42].

3.4.2. Interfacial Action of Fiber-Reinforced Soil. Due to the different elastic moduli of palm fiber and soil, the fiber and soil particles tended to become staggered when shear

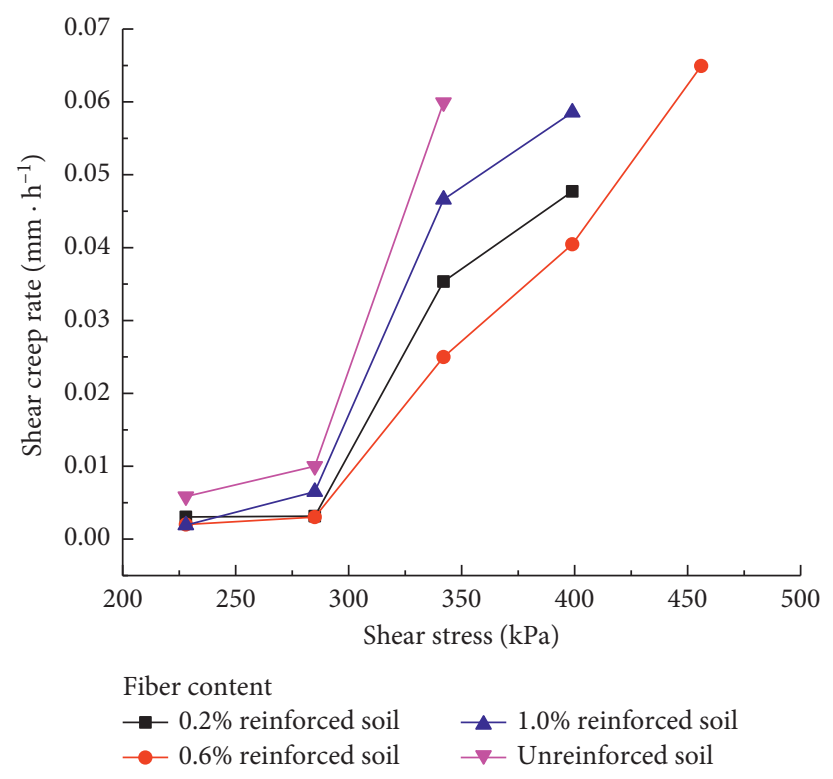

FIGURE 5: Stress-strain rate curves of soil with different fiber contents.

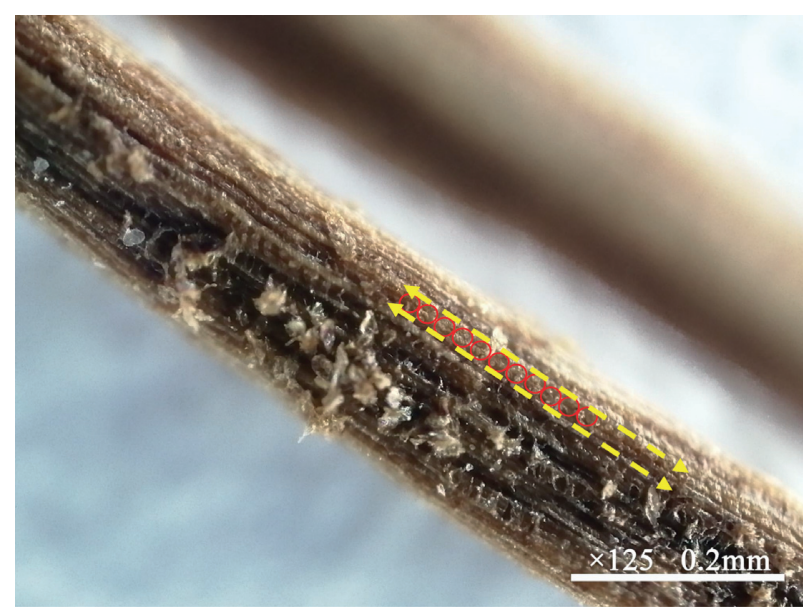

FIGURE 6: Fiber surface morphology $(200 \times$ magnification $)$.

deformation or failure occurred under load, and then interface stress occurred. When fibers in soil are pulled or pulled out, it is necessary to overcome not only the soil particle-fiber bonding effect but also the friction between them. The resulting great resistance restricts the displacement of soil particles and improves the creep mechanical properties of soil.

As shown in Figure 7, at fiber contents of $0.2 \%$ to $0.6 \%$, a large number of fibers are randomly distributed in the soil and interweave to form a "nestled" network structure. This interlocks the soil particles, thus restricting their displacement and deformation and increasing the integrity, strength, and stability of the soil. When one of the fibers is pulled, it affects the other fibers, which bear the force together by forming a three-dimensional stress network so that the load is distributed over a wider area, further improving the fiber's tensile effect. 


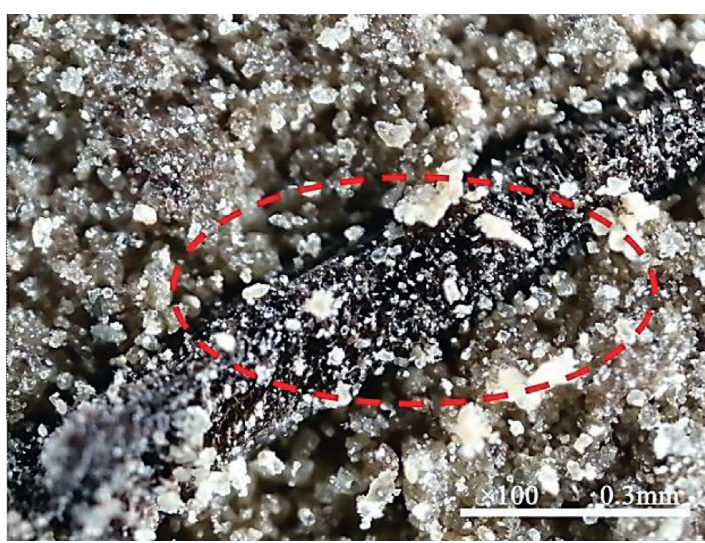

(a)

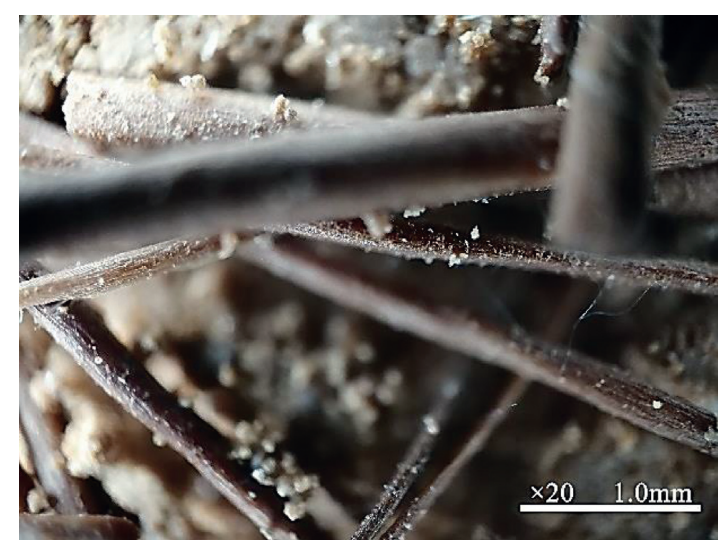

(b)

Figure 7: Distribution and surface characteristics of fibers in palm fiber-reinforced soil. (a) Single and (b) multiple fibers.

As the fiber content increases further (from $0.6 \%$ to $1.0 \%)$, the long-term strength decreases. The reason is that when the fiber content is low, the interfacial action of the reinforced soil is mainly based on interaction between discrete single fibers and soil. With increases in fiber content, the fibers interlace and interweave into a network. In addition to the interaction between single fiber and soil, a three-dimensional network structure is formed to constrain soil deformation, and the effect of reinforcement is further improved. However, when the fiber content increases further, a large number of fibers intertwine and overlap with each other and the reinforcement is not evenly distributed. This prevents the soil particles and fiber from fully contacting, which forms a weak surface and cannot give full play to the role of reinforcement.

\subsubsection{Quantitative Analysis of Soil Pore Structure}

(1) Preparation of Soil Microtest Samples. To study the pore distribution characteristics of soil before and after creep testing, unreinforced soil and $0.6 \%$ reinforced soil (unloaded and equal shear stress is $342 \mathrm{kPa}$ ) were selected for SEM testing.

To ensure the quality of the SEM images and improve the accuracy of the microscopic data, unreinforced and reinforced loess thin-section samples for SEM scanning tests were prepared according to the method of Li et al. [43]. The specific process is as follows: (1) samples obtained before and after creep testing were placed in an oven for drying (as shown in Figure 8(a)) and cut into cylindrical samples of $2 \mathrm{~cm}$ in 00diameter and $2 \mathrm{~cm}$ in height (as shown in Figure 8(b)). (2) To increase the hardness of the cylinder samples, they were injected with epoxy resin. After the samples were consolidated and hardened, the excess soil was ground away with a grinding wheel to reveal the surface to be scanned (Figure 8(c)). The scanning surface was smoothed and polished with a metallographic polishing machine (Figure 8(d)). (3) To increase the conductivity of the soil samples, an ion sputtering instrument was used to sputter the samples with gold (Figures $8(e)$ and $8(f)$ ). Finally, an
SEM (Figure 8(g)) was used to collect microscopic images of the samples.

(2) Image Processing and Quantitative Analysis of Soil Micropores. The SEM images of unreinforced soil and reinforced soil with $0.6 \%$ fiber were introduced into the Particles (Pores) and Cracks Analysis System (PCAS) for microscopic quantitative analysis $[35,44]$. By binarization, particles and pores were automatically identified according to color (black and white, resp.). Firstly, preprocess the SEM image to ensure that the image is clear and prepare for the binarization of the SEM image. Then, by selecting the appropriate gray-level threshold, the pore and background are identified by different gray levels. Finally, convert the SEM image into a binary image, separate the pores from the background, and count the pore microstructure parameters. The image processing results are shown in Figures 9 and 10. The microscopic parameters were obtained, and the pore size, number, and distribution characteristics were quantitatively analyzed.

This paper referred to Lei's classification standard of loess pore obtained by Mercury intrusion method to classify and count the pores in SEM images of direct shear creep test soil samples [45]. Figure 11 shows the results of pore size, pore number, and porosity. In Figure 11, the histogram shows that the pore sizes in unreinforced and reinforced soil before creep loading were mainly within $0-30 \mu \mathrm{m}$. These pores accounted for $96.49 \%$ and $97.21 \%$ of the total pores, respectively. By observing the variation in the broken line graph, it can be seen that, with increases in pore diameter, the porosity of both unreinforced and reinforced soil tended to first increase and then decrease. However, the porosity of unreinforced soil rebounded when pore diameters beyond $100 \mu \mathrm{m}$. The results show that there were large pores in unreinforced soil, and the addition of fiber improved the pore distribution and reduced the number of large pores.

As shown in Figure 11(b), under the effect of creep, large pores are reduced in size while small pores are increased, and the number of pores increases significantly. This is because, in the creep process of soil, particles that are close to each other slip and inlay so that large pores are gradually replaced 


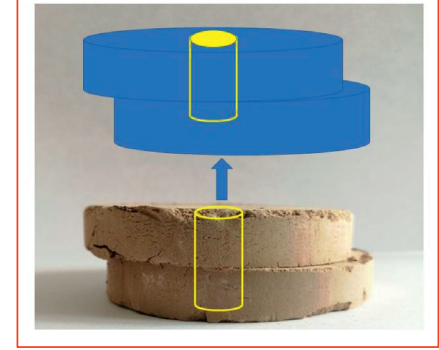

(a)

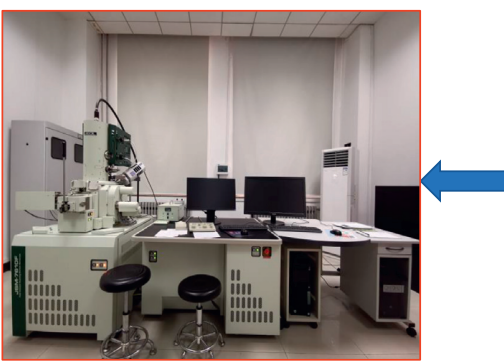

(g)

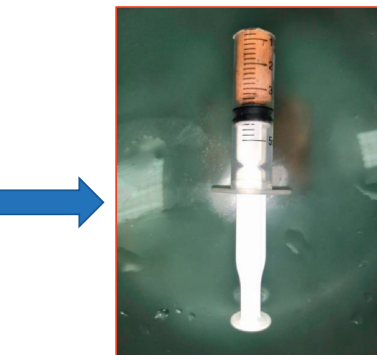

(b)

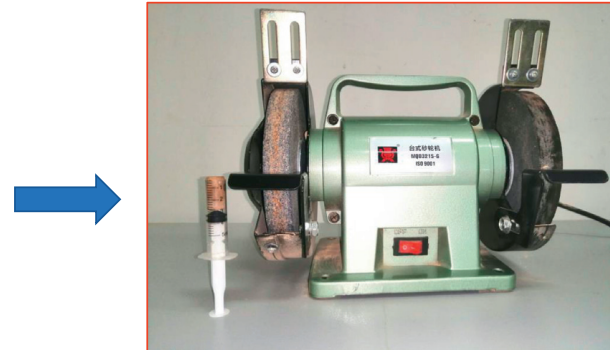

(c)

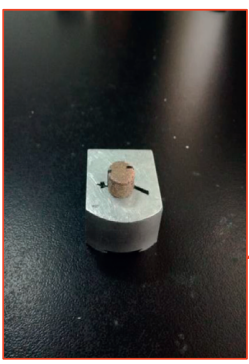

(f)

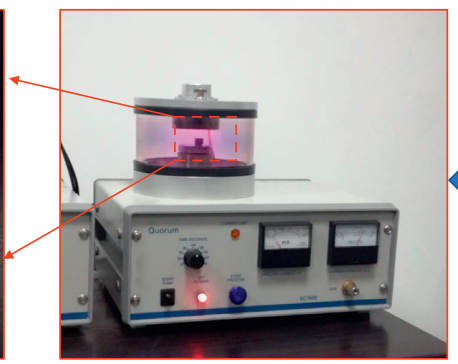

(e)

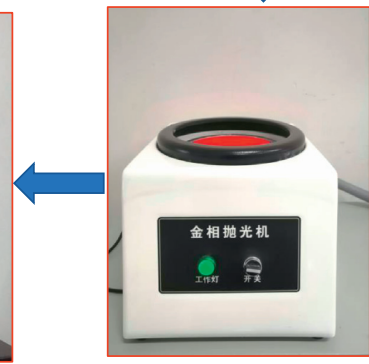

(d)

Figure 8: Scanning electron microscope sample preparation process. (a) Sample after direct shear creep test; (b) cylinder sample; (c) grinding machine used to grind the specimens; (d) polishing machine used for polishing; (e) sputter coater used for spraying samples with gold; (f) sample after being sprayed with gold; (g) scanning electron microscopy.

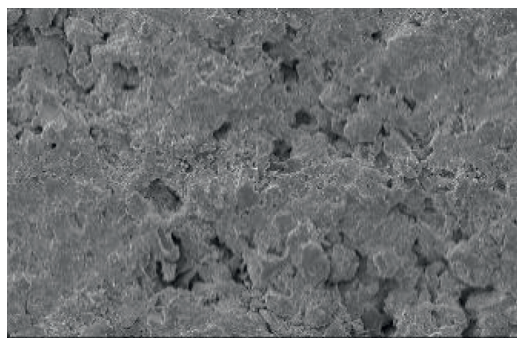

(a)

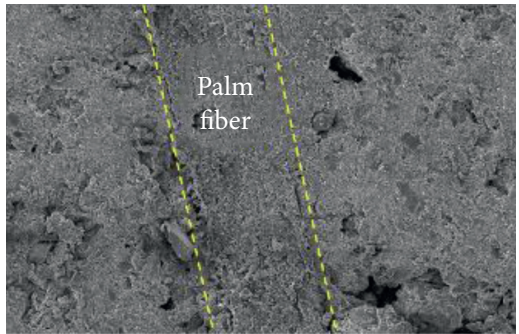

(d)

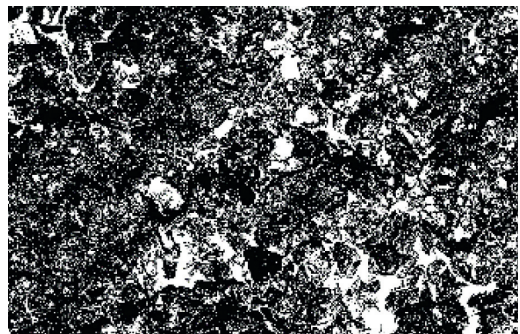

(b)

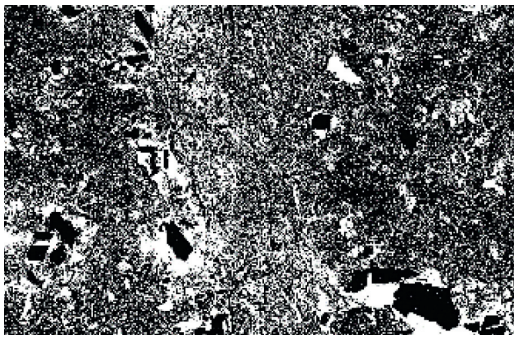

(e)

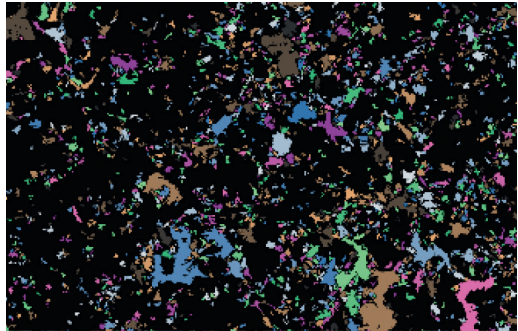

(c)

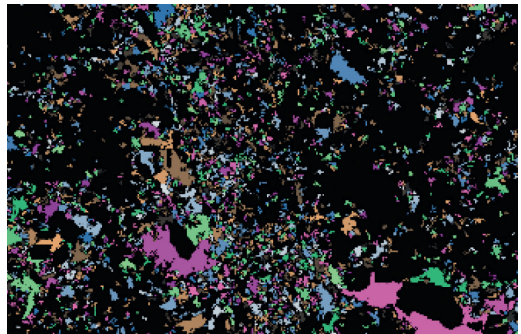

(f)

FIGURE 9: SEM images of unreinforced and reinforced soil before loading. SEM images of unreinforced soil: (a) original; (b) with binary image processing; and (c) with vectorization. SEM images of $0.6 \%$ reinforced soil: (d) original; (e) with binary image processing; and (f) with vectorization.

by small ones, and a large number of small pores are formed. This pore change during the creep process can be considered to follow the principle of pore homogenization, which can also be called the principle of macropore preferential change [46].

This phenomenon was more obvious in the reinforced soil after creep loading. By comparing Figures 11(a) and 11(b), it can be seen that the porosity of unreinforced soil was $23.23 \%$ before creep and $17.97 \%$ after creep, and the porosity decreased by $22.77 \%$. The porosity of reinforced soil was $9.15 \%$ before creep and $6.79 \%$ after creep, and the porosity decreased by $25.79 \%$. According to Figure $11(\mathrm{~b})$, the proportion of pore diameters beyond $30 \mu \mathrm{m}$ in unreinforced soil after creep was $1.08 \%$, while that in reinforced soil was 


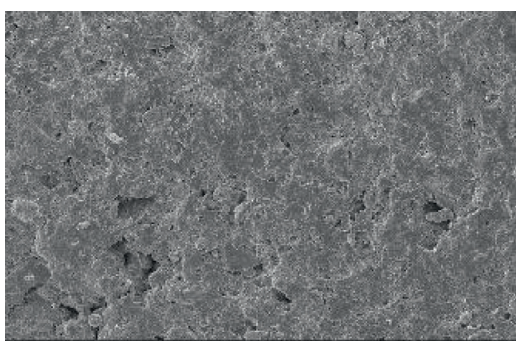

(a)

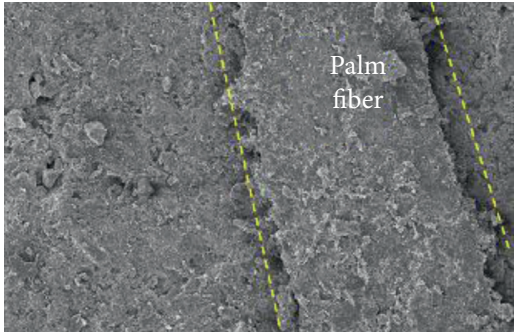

(d)

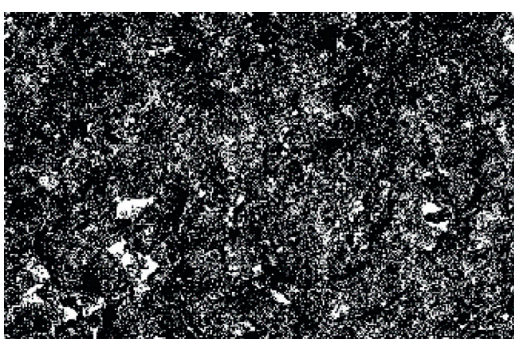

(b)

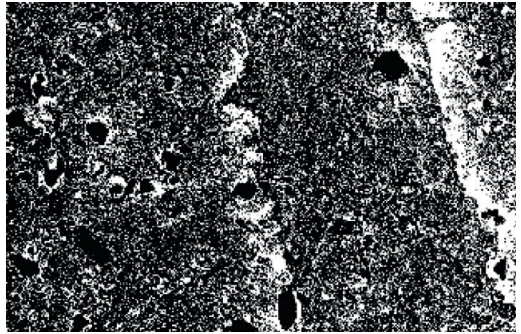

(e)

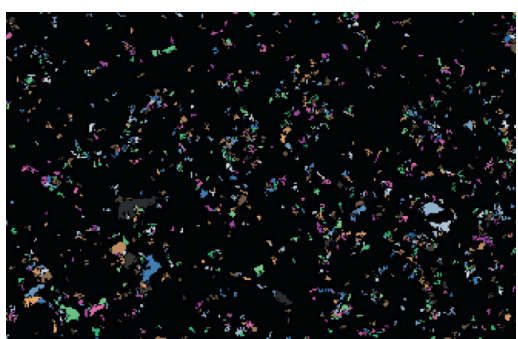

(c)

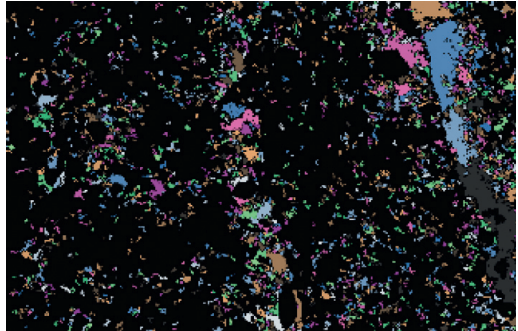

(f)

FIGURE 10: SEM image processing results of unreinforced and reinforced soil under the same shear stress $(\tau=342 \mathrm{kPa})$. SEM images of unreinforced soil: (a) original; (b) with binary image processing; and (c) with vectorization. SEM images of $0.6 \%$ reinforced soil: (d) original; (e) with binary image processing; and (f) with vectorization.

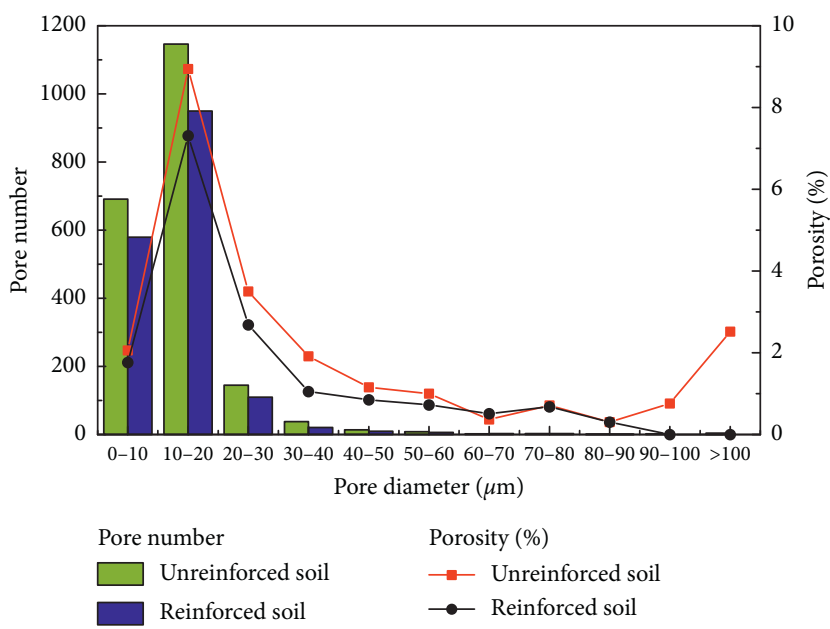

(a)

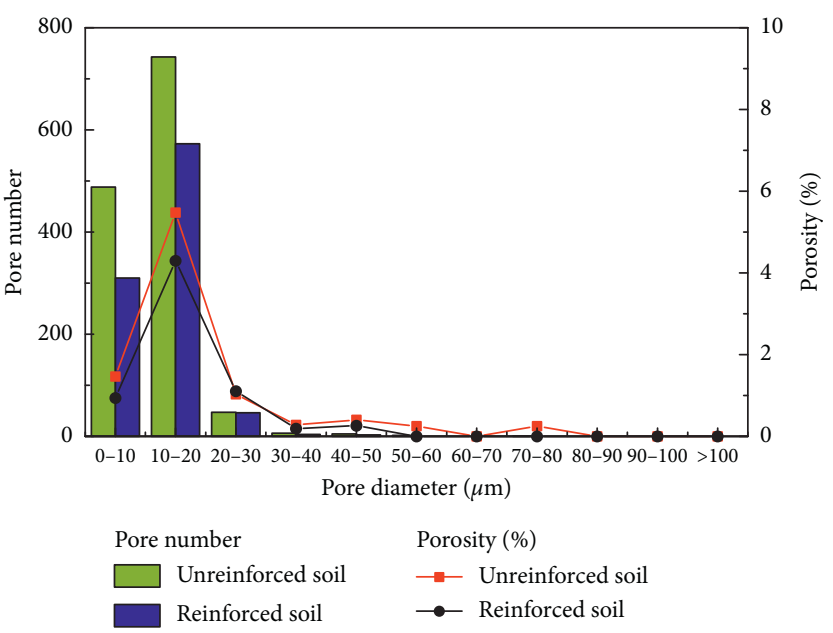

(b)

Figure 11: Porosity and pore number distribution in different diameter range under different loads. Pore distribution (a) before loading and (b) after loading $(\tau=342 \mathrm{kPa})$.

only $0.7 \%$. This indicates that fiber reinforcement can further promote the pore transformation rate under load and reduce the proportion of macropore.

From the microlevel, it can be seen that, due to the addition of fibers, the microstructure of the soil changed, the proportion of large pores decreased, and the number of small pores increased. This means that soil particles and fibers can be in better contact, which is conducive to enhancing the interface effect of fiber-reinforced soil. This result is beneficial to restrain the displacement of soil particles and improve the creep mechanical properties of soil. Under the effect of creep, the soil particles and fibers are close together and inlaid with each other, the contents of large and medium pores in fiber-reinforced soil decreased further, while the proportion of small pores increased further. This result makes the effective contact area between soil particles and fibers further increased, and the interface effect between the reinforcement-soil and the fiber further improved. Therefore, the comparison between the test results of unreinforced soil and $0.6 \%$ fiber-reinforced soil shows that, 
under load, the long-term strength of $0.6 \%$ fiber-reinforced soil is much higher than that of the unreinforced soil in Figures $4(\mathrm{~b})$ and $4(\mathrm{c})$, and the creep velocity of $0.6 \%$ fiberreinforced soil is much lower than that of the unreinforced soil in Figures 5(a) and 5(c).

\section{Conclusions}

In this paper, the creep mechanical properties of palm fiberreinforced soil were studied by direct shear creep tests. The interfacial mechanism of reinforced soil was explored by using polarized light microscopy and SEM. Qualitative and quantitative analyses of the micropore changes in reinforced soil were conducted, and the conclusions drawn were as follows:

(1) The reinforcement had a significant effect on improving the creep characteristics of soil. With increases in fiber content, the deformation and creep rate of the soil were restrained and the long-term strength continued to increase. However, the linear relationship between improvement in the creep property and fiber content was not satisfied. Reinforcement no longer increases when fiber contents are beyond $0.6 \%$.

(2) Observation of the fiber-reinforced soil by polarized light microscopy revealed that the surface of the palm fiber was rough, with grooves and independent pore rooms. Under the actions of friction and extrusion, soil particles were embedded into the grooves and pore chambers, which increases the effective contact area of the soil and increases the interaction at the reinforcement-soil interface. With increases in fiber content, the fibers interweave with each other, forming a "nestled" network structure that restricts the displacement of soil particles and soil deformation and increases the soil strength and integrity.

(3) Quantitative analysis of soil micropores showed that the addition of fibers changes the microstructure of the soil pores; the proportion of large pores decreases and the proportion of small pores increases. The aperture distribution is concentrated in the mediumto-small range. In the process of creep deformation, the pore changes follow the principle of pore homogenization. Large pore structures are destroyed first and transformed into small pores. Compared with unreinforced soil, the porosity of reinforced soil decreases faster, the pore diameter decreases more, and the number of macropores decreases more obviously, which increases contact between the soil particles and fibers.

\section{Data Availability}

The data used to support the findings of this study are available from the corresponding author upon request.

\section{Conflicts of Interest}

The authors declare that they have no conflicts of interest.

\section{Acknowledgments}

The research described in this paper was financially supported by the National Natural Science Foundation of China (Grant no. 41702298). The authors wish to offer their gratitude and regards to the classmates and teachers who contributed to this work.

\section{References}

[1] J. Lovisa, S. K. Shukla, and N. Sivakugan, "Shear strength of randomly distributed moist fibre-reinforced sand," Geosynthetics International, vol. 17, no. 2, pp. 100-106, 2010.

[2] C.-S. Tang, B. Shi, and L.-Z. Zhao, "Interfacial shear strength of fiber reinforced soil," Geotextiles and Geomembranes, vol. 28, no. 1, pp. 54-62, 2010.

[3] I. M. C. F. Pinto, "Effect of short, randomly distributed, polypropylene micro fibers on shear strength behavior of soils," Geosynthetics International, vol. 18, no. 1, p. 2, 2011.

[4] B. Fatahi, T. M. Le, and H. Khabbaz, "Small-strain properties of soft clay treated with fibre and cement," Geosynthetics International, vol. 20, no. 4, pp. 286-300, 2013.

[5] Q. Ma, Y. Yang, H. Xiao, and W. Xing, "Studying shear performance of flax fiber-reinforced clay by triaxial test," Advances in Civil Engineering, vol. 2018, no. 2, 8 pages, Article ID 1290572, 2018.

[6] Y. X. Wang, P. P. Guo, S. B. Shan et al., "Study on strength influence mechanism of fiber-reinforced expansive soil using jute," Geotechnical \& Geological Engineering, vol. 34, no. 4, pp. 1079-1088, 2016.

[7] V. Sharma, H. K. Vinayak, and B. M. Marwaha, "Enhancing compressive strength of soil using natural fibers," Construction and Building Materials, vol. 93, pp. 943-949, 2015.

[8] A. E. M. K. Mohamed, "Improvement of swelling clay properties using hay fibers," Construction and Building Materials, vol. 38, pp. 242-247, 2013.

[9] X. L. Li, Studies on Basic Properties of Palm Fiber, Southwest University, Chongqing, China, 2012.

[10] G. Ranjan, R. M. Vasan, and H. D. Charan, "Probabilistic analysis of randomly distributed fiber-reinforced soil," Journal of Geotechnical Engineering, vol. 122, no. 6, pp. 419426, 1996.

[11] J. Prabakar and R. S. Sridhar, "Effect of random inclusion of sisal fibre on strength behaviour of soil," Construction and Building Materials, vol. 16, no. 2, pp. 123-131, 2002.

[12] T. Yetimoglu, M. Inanir, and O. Esatinanir, "A study on bearing capacity of randomly distributed fiber-reinforced sand fills overlying soft clay," Geotextiles and Geomembranes, vol. 23, no. 2, pp. 174-183, 2005.

[13] P. Vinod, A. Bhaskar, and C. S. Lekshmi, "Triaxial compression of clay reinforced with sand-coir fiber core," Geotechnical Testing Journal, vol. 30, no. 4, pp. 333-336, 2007.

[14] A. A. Adili, R. Azzam, S. Giovanni, and S. Joerg, "Strength of soil reinforced with fiber materials (Papyrus)," Soil Mechanics \& Foundation Engineering, vol. 48, no. 6, pp. 241-247, 2012.

[15] H.-H. Zhu, C.-C. Zhang, C.-S. Tang, B. Shi, and B.-J. Wang, "Modeling the pullout behavior of short fiber in reinforced soil," Geotextiles and Geomembranes, vol. 42, no. 4, pp. 329-338, 2014.

[16] X. Chen, J. Zhang, and Z. Li, "Shear behaviour of a geogridreinforced coarse-grained soil based on large-scale triaxial tests," Geotextiles and Geomembranes, vol. 42, no. 4, pp. 312-328, 2014. 
[17] G. Lei, H. H. Guo, X. Nan et al., "Experimental study on unconfined compressive strength of basalt fiber reinforced clay soil," Advances in Materials Science and Engineering, vol. 2015, Article ID 561293, 8 pages, 2015.

[18] Y. Wang, P. Guo, H. Lin et al., "Numerical analysis of fiberreinforced soils based on the equivalent additional stress concept," International Journal of Geomechanics, vol. 19, no. 11, pp. 4019121-4019122, 2019.

[19] Y. Wang, P. Guo, F. Dai et al., "Behavior and modeling of fiber-reinforced clay under triaxial compression by combining the superposition method with the energy-based homogenization technique," International Journal of Geomechanics, vol. 18, no. 12, pp. 4018171-4018172, 2018.

[20] Y.-X. Wang, P.-P. Guo, W.-X. Ren et al., "Laboratory investigation on strength characteristics of expansive soil treated with jute fiber reinforcement," International Journal of Geomechanics, vol. 17, no. 11, Article ID 04017101, 2017.

[21] C.-S. Tang, D.-Y. Wang, Y.-J. Cui, B. Shi, and J. Li, "Tensile strength of fiber-reinforced soil," Journal of Materials in Civil Engineering, vol. 28, no. 7, Article ID 04016031, 2016.

[22] J. B. Hao, X. M. Wei, J. Yao et al., "Strength characteristics and mesostructure of wheat straw reinforced soil," Journal of Tongji University (Natural Science Edition), vol. 47, no. 06, pp. 764-768, 2019.

[23] J. Z. Li and F. L. Peng, "Experimental research on creep property of clay," Rock and Soil Mechanics, vol. 27, no. 002, pp. 214-218, 2006.

[24] P. C. Wang, Y. S. Luo, L. X. Hu et al., "Research on triaxial creep characteristics and models of remolded loess," Rock and Soil Mechanics, vol. 06, pp. 1627-1632, 2015.

[25] B.-P. Wen and X.-Z. Jiang, "Effect of gravel content on creep behavior of clayey soil at residual state: implication for its role in slow-moving landslides," Landslides, vol. 14, no. 2, pp. 559-576, 2017.

[26] W. Shun, W. Wei, G. W. Jin et al., "Residual-state creep of clastic soil in a reactivated slow-moving landslide in the Three Gorges Reservoir Region, China," Landslides, vol. 15, pp. 2413-2422, 2018.

[27] Z. Kaddouri, O. Cuisinier, and F. Masrouri, "Influence of effective stress and temperature on the creep behavior of a saturated compacted clayey soil," Geomechanics for Energy and the Environment, vol. 17, pp. 106-114, 2019.

[28] H. Tang, D. Zhao, D. P. Wang et al., "Experimental investigation of creep behavior of loess under different moisture contents," Bulletin of Engineering Geology and the Environment: The Official Journal of the IAEG, vol. 79, no. 8, 2020.

[29] Y. Xu and P. Guo, "Disturbance evolution behavior of loess soil under triaxial compression," Advances in Civil Engineering, vol. 2020, no. 3, 14 pages, Article ID 4160898, 2020.

[30] P. Guo, X. Gong, and Y. Wang, "Displacement and force analyses of braced structure of deep excavation considering unsymmetrical surcharge effect," Computers and Geotechnics, vol. 113, Article ID 103102, 2019.

[31] P. Y. Hicher, H. Wahyudi, and D. Tessier, "Microstructural analysis of inherent and induced anisotropy in clay," $\mathrm{Me}$ chanics of Cohesive-Frictional Materials, vol. 5, no. 5, pp. 341-371, 2000.

[32] X. Bai, P. Smart, and X. Leng, "Polarizing micro-photometric analysis,” Géotechnique, vol. 44, no. 1, pp. 175-180, 1994.

[33] R. Smart and X. Bai, "Change in microstructure of kaolin in consolidation and undrained shear," Géotechnique, vol. 47, no. 5, pp. 1009-1017, 1997.
[34] Y. Wang, P. Guo, X. Li et al., "Behavior of fiber-reinforced and lime-stabilized clayey soil in triaxial tests," Applied Sciences, vol. 9, no. 5, 2019.

[35] C. Liu, B. Shi, J. Zhou, and C. Tang, "Quantification and characterization of microporosity by image processing, geometric measurement and statistical methods: application on SEM images of clay materials," Applied Clay Science, vol. 54, no. 1, pp. 97-106, 2011.

[36] A. Lloret, M. V. Villar, M. Sánchez, A. Gens, X. Pintado, and E. E. Alonso, "Mechanical behaviour of heavily compacted bentonite under high suction changes," Géotechnique, vol. 53, no. 1, pp. 27-40, 2003.

[37] H. Lei, H. Lu, X. Wang, Q. Ren, and B. Li, "Changes in soil micro-structure for natural soft clay under accelerated creep condition," Marine Georesources \& Geotechnology, vol. 34, no. 4, pp. 365-375, 2016.

[38] X. Xie, S. Qi, F. Zhao et al., "Creep behavior and the microstructural evolution of loess-like soil from Xi'an area, China," Engineering Geology, vol. 263, Article ID S217638872, 2017.

[39] Y. D. Zhang, Y. F. Sha, J. Chen et al., "Experimental study on creep behavior of red clay of existing foundation in Guiyang City," China Karst, vol. 38, no. 04, pp. 627-634, 2019.

[40] M. X. Zhao and W. Koves, "Isochronous stress-strain method with general state of stress and variable loading conditions for creep evaluation," Journal of Pressure Vessel Technology, vol. 134, no. 5, Article ID 51205, 2012.

[41] W. Koves and M. X. Zhao, "Comparison of the isochronous method and a time-explicit model for creep analysis," in Proceedings of the AMSE Pressure Vessels \& Piping Conference, Chicago, IL, USA, July 2008.

[42] C. S. Tang, B. Shi, and K. Gu, "Microstructural study on interfacial interactions between fiber reinforcement and soil," Journal of Engineering Geology, vol. 19, no. 04, pp. 610-614, 2011.

[43] X. A. LI, L. LI, Y. Song et al., "Characterization of the mechanisms underlying loess collapsibility for land-creation project in Shaanxi Province, China-a study from a micro perspective," Engineering Geology, vol. 249, pp. 77-88, 2018.

[44] C. Liu, C.-S. Tang, B. Shi, and W.-B. Suo, "Automatic quantification of crack patterns by image processing," Computers \& Geosciences, vol. 57, pp. 77-80, 2013.

[45] X. Y. Lei, "Pore types and collapsibility of loess in China," Science in China (Series B), vol. 17, no. 12, pp. 1309-1318, 1987.

[46] C. Y. Zhou and C. M. Mu, "Relationship between microstructural characters of fracture surface and strength of soft clay," Journal of Geotechnical Engineering, vol. 10, pp. 11361141, 2005. 